\title{
AS CONTRIBUIÇÕES DE INTERVENÇÃO NO DOMÍNIO ECONOMICO E A CONSTITUIÇÃO
}

Ives Gandra da Silva Martins*

RESUMO: O autor faz uma análise do perfil constitucional das contribuiçöes de intervençăo no domínio econômico, referidas no artigo 149 da Constitução Federal de 1988, mostrando a vinculação destas à ordem econômica, fazendo surgit o direito econômico.

ABSTRACT: The author makes an analysis of the Intervention Taxes in economical domain, related in article 149 of the Federal Constitution of 1988, showing the entailing of them to the economic order, bringing up to discussion the economic law.

RESUMEN: El autor hace un análisis del perfil constitucional de las Contribuciones de Intervención en el dominio económico, relacionadas en el artículo 149 de la Constitución Federal de 1988, demostrando él vinculo de éstos con la orden económica, haciendo aparecer to Derecho Económico.

PALAVRAS CHAVE: Constituição. Contribuiçôes de Intervençâo. Domínio Económíco, Direito Econômico.

KEY-WORDS: Constitution. Intervention taxes, Economic domain. Economic law.

PALABRAS-LLAVE: Constitución. Contribuciones de Intervención. Dominio económico. Derecho económico.

\footnotetext{
"Professor Emerito das Universidades Mackenzic, Paulista e Escola de Comando Estado Maior do Exćrcito, Presidente do Conselho de Estudos furidicos da Fedenacou do Contéro do Estado de Săo Paulo e do Centro de Extensão Unrversitária - CEU. Emailt ivesgandraiogandramarinas sadvor
} 
O perfil constitucional das contribuições de intervenção no domínio econômico - apenas referidas no artigo 149 da lei suprema- está vinculado à ordem econômica, Título VII da Magna Carta e, em especial, à dualidade da iniciativa econômica.

Tal temática tem sido objeto de permanente análise, muito embora ainda hoje não pacificada na doutrina e na jurisprudência.

Discuti a questão, com a participação de inúmeros professsores da área, no $1^{\text {a }}$ Simpósio Nacional de Direito Económico do Centro de Extensão Universitária, à luz da Constituição anterior.

As conclusóes do referido conclave - ainda quando a Lei Suprema não aludia à existência de um ramo do direito, com o batismo de "econômico"-, foram no sentido de que a ordem econômica comporta duas claras atuações de seus agentes, ou seja, na exploração de atividades de conteúdo mercantil, abrangendo, inclusive, os serviços, e na prestação de serviços públicos com densidade econômica. Na primeira, prevaleceriam as normas de direito privado, com a presença indireta dos ramos de direito público relacionados; na segunda, as regras do direito público seriam mais relevantes, principalmente as de direito administrativo, embora também com influência indireta do direito privado '.

A meu ver, a Constituição de 1988 veio consagrar essa linha de interpretação, conforme já procurei demonstrar em inúmeros artigos e trabalhos juridicos.

Toda a ordem econômica está voltada a um liberalismo-social ou a um socialismo liberal, que, no dizer de Miguel Reale e Oscar Corrêa, compõem a terceira via da economia moderna ${ }^{2}$. Ambos autores mos-

O Caderno n. 1 de Direito Econônico do Centro de Extensão Universituria e Editora Resenha Tributária, sob o tutulo "Disciplina Junidica da Iniciativa Econômica" hospedou trabalhos dos segaintes autores: Attila de Sonza Leão Andrade Jx, Edvaldo Brito, Eros Roberto Grau, Fábio Nusdeo, Geraldo de Camargo Vidigal, Ives Gandra da Silva Martins, Jamil Zantut, José Carlos Graça Wagner, José Tadeu de Chiara, Luiz Felizado Bartoso, Raimundo Bezerra Falcäo, Roberto Rosas e Washington Peluso Albino de Souza (São Paulo, 1983).

2 Miguel Reale escreve: "Como se verá, a Queda do Muro de Berlin somente surpreendeu os intelectuais dominados pelo ópio do marxismo, porquanto a precariedade do regime sovietico já havia sido mais do que demonstrada pelos novos doutrinadores do liberalismo, os quais também puseram à nostra todos os equívocos em que se enredavam os partidarios da Social-Democracia, cada vez mais incapaz de se afirmar como soluçẫo plausivel e segura, visto padecer do mesmo mal do comunismo, que era a vinculação às idéias marxistas da luta de classes e da economia dirigida, posta como fundamento único e legitimador do Estado.

Foi assim que, se, de um lado, os liberais extremados se deixavam fascinar pelos sortilegios da livre concortencia, apontada como única fonte de bemestat, de olitro, os social-democratas mais conscientes deram-se conta da necessidade de proceder à revisăo de suas diretrizes básicas.

E desse contraste ou entrechoques de idéias que iria emergir o fato político mais relevante de nosso tempo, o da conpergência das ideologias, năo no sentido de uma solução única, mas sim no sentido de recíprocas influências entre elas, levando a diversos programas revisionistas" (O Estado Democrático de Direito e o Conflito das Ideologias, Ed. Saraiva, 1998, p. XI/XII). 
tram que a economia de mercado, perfilada pelo constituinte de 1988 , está temperada por valores sociais, ao ponto de os dois fundamentos maiores do artigo 170 referirem-se, de um lado, à valorização do trabatho humano e, de outro, à livre iniciativa ${ }^{3}$. Esta última só é possível em face da livre concorrência (art. 170, inciso IV) e está balizada por dois mecanismos de cerceamento de desvios, quais sejam, na ponta da produção e circulação de mercadorias e serviços, pelo controle do abuso do poder econômico (art. 173, $\S 4^{a}$ da C.F.), e na ponta do consumo, à proteção ao direito do consumidor ( $5^{\text {a }}$, inciso XXXII e 170 , inciso $\left.V\right){ }^{4}$.

A opção pela economia de mercado, todavia, torna-se clara no artigo 174, "caput", cuja dicção é a seguinte:

"Como agente normativo e regulador da atividade econômica, o Estado exercerá, na forma da lei, as funçōes de fiscalização, incentivo e planejamento, sendo este determinante para o setor público e indicativo para o setor privado" (grifos meus), tornando o planejamento apenas indicativo para o segmento privado, embora obrigatório para o setor público, apesar de a disciplina legal de incentivos e fiscalização ser comum aos dois ramos ${ }^{5}$.

$\mathrm{O}$ artigo 173, em seu "caput", não alterado pela EC. n. 19/98, declara que: "Ressalvados os casos previstos nesta Constituição, a exploração direta de atividade econômica pelo Estado só será permitida quando necessária aos imperativos da segurança nacional ou a relevante interesse coletivo, conforme definidos em lei", apenas permitindo, na explonação da atividade econômica, a presença do Estado para atender: 1) a interesse coletivo relevante ou 2) imperativos da segurança nacional.

Nas duas hipóteses, os comandos normativos a serem seguidos são próprios do direito privado, mais amplos no texto original $\left(170, \S \S 1^{\mathrm{a}} \mathrm{e}\right.$

\footnotetext{
"Mignel Reale, "O Estado Democrático de Direito e o Conflito das Ideologias", Ed. Saraiva, 1998 e Oscar Corrềa, "O Sistema Político-Econômico do Futuro: O Societarismo", Ed. Forense Universitánia, 1994.

4 Os dispositivos estâo assim redigidos: "Art. $170 \mathrm{~A}$ ordem economica, fundada na valorizacăo do trabalho humano e na livre iniciativa, tem por fim assegurar a todos existência digna, conforme os ditames da justica social, observados os seguintes principios: ...IV. livte conoorrência; V. defesa do consumidor";

"Art. $173-\S 4^{4}-$ A lei reprimira o abuso do poder econômico que vise à dominação dos mercados, à eliminaça da concorréncia e ao aurnento arbitrário dos lucros";

"Art. 5" - XXXII. O Estado promoverá, na forma da lei, a defesa do consumidor".

Manoel Gonçalves Ferreira Filho comenta o dispositivo: "PLANEJAMENTO: Como se sabe, há dois tipos de planejamento. Um, de caráter indicativo, visa a orientar as agentes económicos, propondo metas, indicando investimentos, mormente estatais etc. Este é compativel com a economia soctal de mercado, embora seja renegado pelo liberalismo clássico.

O outro, o planejamento de caráter compulsório, aqui chamado de determinante -mas por muitos designado por planificação para fáci distinção en telação do primeiro- é típico da economia centralizada. Por meio dele, procura-se substituir o mercado por avaliaçoes administrativas de que defluen ordens sobre o cálculo de quantidades fisicas e valores de caráter meramente contábii (cf. meu Direito Constitucional Econômico, cit, p. 10).

Diffcl é conceber a possibilidade de um planejamento compulsorio, ainda que apenas para o chamado setor público da economia, no quadro de um economia de mercado, a qual indiscutivelmente resulta da Consuiuçäo em estudo" (Comentários à Constituição Brasileira de 1988, vol. 4, Ed. Sarava, 1995, p. 15).
} 
$\left.2^{2}\right)$, e mais restritos no texto da E.C. n. $19 / 98\left(173, \S 1^{\mathfrak{a}}\right)$, visto que certas normas pertinentes ao direito administrativo passaram a ser exigidas expressamente, a partir de $1998^{6}$.

Os parágrafos dos dois Textos Supremos estão assim redigidos:

Constituição de 1988 (redação original): "Art. 173 ...

$\S 1^{\underline{a}}$ A empresa pública, a sociedade de economia mista e outras entidades que explorem atividade econômica sujeitam-se ao regime jurídico próprio das empresas privadas, inclusive quanto às obrigações trabalhistas e tributárias.

$\$ 2^{a}$ As empresas públicas e as sociedades de economia mista não poderão gozar de privilégios fiscais não extensivos às do setor privado";

E.C. n. 19/98: "Art. 173 ...

$\S 1^{\underline{a}}$ A lei estabelecerá o estatuto jurídico da empresa pública, da sociedade de economia mista e de suas subsidiárias que explorem atividade econômica de produção ou comercialização de bens ou de prestação de serviços, dispondo sobre:

I. sua função social e formas de fiscalização pelo Estado e pela sociedade;

II. a sujeição ao regime jurídico próprio das empresas privadas, inclusive quanto aos direitos e obrigações civis, comerciais, trabalhistas e tributários;

III. licitação e contratação de obras, serviços, compras e alienações, observados os princípios da administração pública;

IV. a constituição e o funcionamento dos conselhos de administração e fiscal, com a participação de acionistas minoritários;

V. os mandatos, a avaliação de desempenho e a responsabilidade dos administradores" (grifos meus).

Ora, em nenhum momento o artigo 173 comporta a exploração de serviços públicos, mas apenas a exploração de atividades econômicas -dá a prevalência do direito privado-, lembrando-se que o $§ 1$ â , na redação da E.C. n. 19/98, refere-se à:
a) exploração de atividade econômica de
(b) produção e

Celso Riberro Bastos preleciona: "Este preceito, muito embora tenha sido modificado pela Emenda n. $19 / 98$, ainda assim guarda grande similitude com o $\S 2^{2}$ do art. 170 da Constituição de 1967 , que recebeu nova redação con a Emendia n. 1, de 1969 , que tezava: "Ş $2^{\underline{a}} \mathrm{Na}$ exploraçäo, pelo Estado, da atividade económica, as empresas públicas e as sociedades de economía mista reger-se-ão pelas nomas aplicaveis às cmpresas privadas, inclusive quanto ao direito do trabalho e ao das obrigaçoes".

E um parafafo muito importante para revelar a indole da organizaça juridica da nossa economía. Ele desempenha um papel de ordem sistemática que transcende em muito o comando que encerra. Neste parágrafo, especificamente no seu ine. II, agasalha-se a idéa de que é possivel ao Estado, através de pessoas descentralizadas, desempenhar um papel assemelhado aquele cumprido pelas empresas privadas. Fixourse no nosso dircito crença de que essa convivência é possivel. Assim o que se procura É que as empresas publicas, as sociedades de economia mista e suas subsiduarias que explorem atividade econônica subnetam-se ao regime jurídico previsto para as empresas privadas" (Comentários à Constituição do Brasil, $7^{\text {a }}$ vol., Ed. Saraiva, 2000, p.67). 
comercialização (c) de bens ou (d) prestação de serviços sem qualquer adjetivação .

Ocorre que, repetidas vezes, o Estado pode intervir em área de prestação de serviços ou comercialização de bens por interesse coletivo relevante ou imperativos de segurança nacional, sem que tais serviços ou circulação de bens possam ser considerados serviços públicos, como, por exemplo, já aconteceu durante a segunda guerra mundial, em que houve período de racionamento de alimentos (leite, pão, etc.). Poderia, se quisesse, criar empresas para explorar tais atividades. Mais recentemente, na importação da borracha, instituiu a contestada TORMB (taxa de organização e regulamentação do mercado da borracha), objetivando regularizar segmento descompassado da economia. Durante o conflito de 1939/45, a distribuição de combustíveis passou a ser de segurança nacional, assim como a produção da borracha. E a "Petrobrás" surgiu, no fim da década de 40, como imperativo de segurança nacional, sem que se possa dizer que a extração, produção e comercialização de combustíveis sejam serviços públicos.

Desta forma, a dicção constitucional sinaliza no sentido de que imperativos de segurança nacional e interesse público relevante podem conformar exploração de atividades econômicas que impliquem serviço, no texto constitucional, sem que sejam necessariamente públicos.

O segundo regime jurídico para atuação do Estado na prestação de serviços públicos com densidade econômica, desenhado está no "caput"

No volume 7 dos Comentários que Celso Ribeiro Bastos e eu elaboramos, lè-se como nota de rodapé n. 1 na pagina 67 o seguinte: "No direito francess, por exemplo, há dois tipos clásicos de empresas públicas. Em primeiro lugar aparecem aquelas com estatuto de sociedade; em segundo vêm as empresas com estatuto de estabelecimento público.

A distinção baseia-se, fundamentalmente, na natureza do serviço que uma e outra prestam. Justamente em funçăo da natureza das tarefas levadas por essas empresas a que se vai descobrir qual o regime jurídico aplicável, numa graduaçåo que vai desde um regime quase puro de direito público (caso dos estabelecimentos públicos desempenhando serviço público) até um regime quase puro de direito privado (sociedades públicas de caráter comercial e industral, que atuam paralelamente, no mercado, com as empresas privadast. Vale dizer que tal critério foi criado pela doutrina francesa, não constando em texto legal algum ( $f$. a respeito Luís S. Cabral de Moncada, Direito Economico, 2a ed., Coimbra Ed. p. 190 , nota de rodapé).

" O artigo 21 e $\$ 1^{\text {A }}$ da Lei n. $5227 / 67$ estava assim redigido: "Art. 21 - E institúda a taxa de organizaçäo e regulamentaçäo de mercado da borracha, de natureza especifica e incidente sobre as borrachas e látices vegetais e quimicas, nacionals e estrangeiras.

$\$ 1^{*}$ Compete ao Conselho Nacional da Borracha estabelecer as aliquotas da taxa a que se refere este artigo para cada categoria de elastômeros, não podendo àquelas exceder a 1/20 (vinte avos) do valor de produção das borrachas e látices nacionais e do preço fob. dos produtos importados". 
do artigo 175 da C.F., sendo seu discurso o seguinte: "Incumbe ao Poder Público, na forma da lei, diretamente ou sob regime de concessão ou permissão, sempre através de licitação, a prestação de serviços públicos" (grifos meus).

Aqui, ao contrário do $\$ 1^{\text {a }}$ do artigo 173 , nitidamente o constituinte fala em serviços públicos e não apenas em serviços, sendo este regime de direito administrativo, devendo, por conseqüencia, as empresas privadas que nele atuem seguir as estritas regras daquele ramo da árvore jurídica?

Não há como confundir os dois regimes. São distintos. No primeiro, o Estado atua como agente vicário na exploração própria da atuação particular, regida por normas que pertinem ao direito privado e, no segundo, o segmento privado pode atuar como agente acólito do Estado na prestação de serviços públicos, que não se confundem com os aspectos pertinentes ao artigo $173^{10}$.

Não consigo vislumbrar outra interpretação, tendo procurado expor, em inúmeros estudos, esta minha inteligência-que reitero no presente trabalho-, ainda recentemente o fazendo, em palestra, perante ministros da Suprema Corte e do Superior Tribunal de Justiça, em Seminário Juridico sobre Concessões em Foz do Iguaçu da Escola Nacional da Magistratura e da Academia Internacional de Direito e Economia (8/6/2001).

Ora, as contribuições de intervenção no domínio econômico só podem referir-se ao regime jurídico do artigo 173 , visto que aquele de prestação de serviços públicos, diz respeito à própria atuação do Estado na ordem econômica.

Centrado, pois, nesta análise é que entendo ser a contribuição imposição excepcio-

Diogo de Figuaredo esclarece: "Os instrumentos de intervençäo do Estado na ordem economica, por estarem estabclecidos como exceçes aos princípios constitucionais da denocracia econômica, tidos como

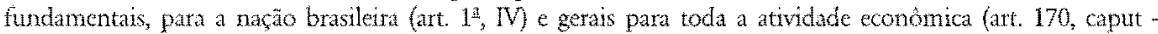
livre iniciatua- $e$ inciso IV livre concorrência), estão taxativamente previstos na propria Carta Magna.

$\mathrm{Mas}_{3}$ difententente da sistemática utilzada para a enunciação dos princípios gerais da atividade economica, os preceitos definitorios das instutuçós interventivas na economia ficaram disseminadas em vários Capítulos, de quatro distintos Títulos (IV, VII, VII e IX) da Constituiçấo.

Essas instituiçoes interventivas se classificam em quatro ipos: regulatórias, concortenciais, monopolistas e sancionatórias. Pela intervenço regulatónia, o Estalo impóe una ordenação coacta aos processos econômicos; pela intervença concorrencial, o Estado propoese a disputar com a sociedade no desempenho de atividades econômicas empresariais; pela intervenço monopolista, o Estado se impòe em exclusividade na exploraça economica de certos bens ou serviços; pela intervenço sancionatóna, o Estado pune os abusos e excessos praticados contra a ordem econômica e financeita, a economia popular e certos interesses gerais de indole económica" (Curso de Direito Administrativo, Ed. Forense, 11a ed, 1996, p. 365/366).

10 Escrevi: "O Estado, sobre näo poder ter qualquer espécie de preferôncha na sua atuaçäo econômica em relaça ao setor privado, somente é chamado a participar de tal processo para suprir, complementar, preencher treas nào atendidas pelo mais vocacionado a tal atividade, que é o da livre iniciativa.

A tai atuação vicána sem privilégios, denomina a doutrina de "intervençăo concontencial, no que me parece que bem rotulou tal secundária participacăo do Estado na Economia.

Pelo artigo 175, o regime iurídico do serviço público, com densidade económica, faz do Estado o agente principal e o sujeito privado mero coadjuvante, pelos mecanismos da concessão, permissäo e autoriza ção" (A Constituiç̃o Aplicada 7, Ed. CEJU, 1993, p. 112). 
nal e extraordinária, apenas possivel em casos de marcante descompasso de mercado. Fora desta rara hipótese, entendo não ser possível a utilização de tal mecanismo tributário para aumentar a arrecadação de uma Federação maior que o PIB.

Nada obstante a carga tributária de $33 \%$ do PIB, as 5.500 entidades federativas, incapazes de cortar despesas de estruturas governamentais esclerosadas, orquestram movimento nacional, nas 3 esferas de Casas de Legislativas, para aumentar, sobre a sociedade brasileira, o peso da imposição tributária.

A União principia a dar sinais de que, esgotados os caminhos clássicos da imposição, pretende utilizar-se, largamente, de tributo apenas mencionado no art. 149 da Constituição Federal e que constitui uma das 3 espécies de contribuições especiais, ou seja, aquela de intervenção no domínio econômico ${ }^{11}$.

Afora a menção no artigo 149 da lei suprema, que reproduzo: "Compete exclusivamente à União instituir contribuições sociais, de intervenção no domínio econômico e de interesse das categorias profissionais ou econômicas, como instrumento de sua atuação nas respectivas áreas, observado o disposto nos arts. 146, III e 150, I e III, e sem prejuizo do previsto no art. 195, $\$$ $6^{\text {a }}$, relativamente às contribuições a que alude o dispositivo".

Não há nesse dispositivo qualquer outra indicação sobre seu perfil, razão pela qual já se vislumbra, na discussão das leis financeiras que compõem as leis orçamentárias, nítida tendência de burocratas, políticos e juristas, que acreditam no Estado utópico, para exploração deste novo veio, antes inexplorado.

Detecto, em tais tentativas, manifesta miopia constitucional -prefiro não detectar "má-fé impositiva"-, visto que o campo de incidência de tais contribuições está, nitidamente, delineado na Constituição, ou seja, no artigo 170 "caput", incisos II e IV e no "caput" do artigo $1744^{12}$.

A contribuição de intervenção no domínio econômico deve respeitar a livre iniciativa ("caput" do art 170 e inciso II), a livre concorrência (inc. IV do artigo 170) e o planejamento meramente indicativo para o setor privado (art. 174).

Estes artigos têm a seguinte redação:

"Art. 170 A ordem econômica, fundada na valorização do trabalho humano e na livre iniciativa, tem por fim assegurar a todos existência digna, con-

1. Escrevi: "As outras duas especies (intervenção no dominio econômico e interesse das categorias sociais ou econônióas) só se justificam na medida em que o capítulo da ordem econômica ou social o pertnita. De qualquer fotma, as contribuicoes especiais näo podem ser cobradas, por sua vinculaçäo, além dos custos necessários aos serviços e finalidades a que se destinam" (Comentários à Constituição do Brasil, 6: vol, tomo I, Ed. Saraiva, 2001, p. 144).

12 Gastäo Alves de Toledo ensina: "Iniciaimente, cabe indagar acerca da acepção conferida aos termos "intervençäo" e "dominio econômico" pelo texto constitucional. Com efeito, intervir em algo significa praticar um ato de "meter-se de permeio, vir ou colocar-se entre, ingerir-se ...", ou seja, aritude de quem não é parte, nem cstá vinculado ao fato ou "dominio" sobre os quais pretende agir, e que se desenvolve "para dentro" ou em direção a esse"meio", visando a algum resultado. Por sua vez, parece-nos que a expressão "dominio econômico" aponta para o âmbito de atuaçăo no qual o Estado não opera, a näo ser em caráter excepcional (exploração direta da atividade econômica monopolizada, ou năo), isto é, o campo da economia privada, não tendo sido aqui conferido outro sentido a esses vocábulos" (Contribuiçoes de Intervençăo no dominio econômico e figuras afins, Dialética, 2001, p. 257). 
forme os ditames da justiça social, observados os seguintes princípios:
II. propriedade privada;
IV. livre concorrência”;

"Art. 174 Como agente normativo e regulador da atividade econômica, o Estado exercerá, na forma da lei, as funções de fiscalização, incentivo e planejamento, sendo este determinante para o setor público e indicativo para o setor privado" (grifos meus) ${ }^{13}$.

Como se percebe, sendo a contribuição de intervenção no domínio econômico instrumento de planejamento econômico, à nitidez, não pode ser utilizado de forma determinante para o setor privado, e, principalmente, para segmentos que não estejam desregulados, descompassados ou vivenciando evidente crise de competitividade ou de subsistência. Sendo um instrumento interventivo, apenas pode ser adotado excepcionalmente e quando detectado desequilíbrio de mercado, que deva ser superado. Caso contrário, a contribuição conformaria uma forma de planejamento determinante para o segmento privado, o que vale dizer, se tornaria um tributo maculador da lei suprema.

A ordem econômica, na Constituição, adotou clara opção pela economia de mercado, não permitindo sequer, à luz do art. 173, que o Estado

13 Escrevi: "Não contente em consagrar a livre concorrência -e o tabelamento e o congelamento eliminariam a liberdade de concorrência para impor regras que o governo entendesse válidas para a economia-, houve por bem o constituinte, ainda, em declarar que todo o planejamento macroeconômico só poderá ser determinante para o setor público, mas nunca para o setor privado.

Assim é que fez o art. 174 ser veiculado com a seguinte dicção: "Como agente normativo e regulador da atividade econômica, o Estado exercerá, na forma da lei, as funções de fiscalização, incentivo e planejamento, sendo este determinante para o setor público e indicativo para o setor privado" (grifos meus), a qual declara que, como agente normativo e regulador da atividade econômica, poderá, o Estado, atuar de três formas, a saber:

a) fiscalização;

b) incentivo;

c) planejamento.

A fiscalização, mesmo que não tivesse o constituinte se referido a tal atividade, é ela insita, inerente, própria do Estado. Seu poder regulatório ou sua intervenção regulatória é, fundamentalmente, de fiscalização para verificar se as leis, que se conformam aos princípios constitucionais, estão sendo respeitadas pelos governos e pela sociedade.

O incentivo é forma própria de atrair investimentos. Não se deve esquecer a lição de Paul Samuelson, que sugere espécie de "congelamento" e "tabelamento", por livre opção das partes, via estímulo fiscal, ou seja, o Estado sugere que as empresas mantenham seus preços abaixo da inflação, dando-lhes em contrapartida redução de tributos.

O certo é que o estímulo, como forma regulatória de atuação no mercado por parte do governo, permite a comprcensão de uma economia de mercado, em que os agentes econômicos devem ser induzidos e não obrigados a agir de determinada maneira.

$\mathrm{E}$, à evidência, no que concerne ao planejamento econômico é este determinante tão-somente para o setor público, mas nunca para o setor privado" (Aspectos constitucionais do Plano Collor I e II, Forense Universitária, Rio de Janeiro, 1991, p. 180/1). 
atue no setor privado, a não ser em casos de relevante interesse coletivo ou imperativos de segurança nacional. Fora destas hipóteses, pode prestar serviços públicos com densidade econômica (art. 175), mas não pode participar da exploração de atividades pertinentes de iniciativa particular ${ }^{14}$.

Ora, a instituição, como mecanismo regulatório, de uma contribuição de intervenção -as regras do art. 174 não são interventivas-apenas é de ser admitida se o mercado estiver desregulado.

Não é de se aceitar, portanto, os diversos projetos que circulam no Congresso Nacional, objetivando onerar o contribuinte, à luz de uma política arrecadatória, para atingir os mais variados aspectos da atuação econômica do segmento privado. Se aprovados, a intervenção não será regulatória, mas desregulatória, pois onerará ainda mais a classe empresarial já suficientemente sufocada por tributos de uma arcaica estrutura impositiva que, nada obstante as falas governamentais, jamais foi alterada para melhor.

$\mathrm{Na}$ linha do meu pensamento, já se filiam juristas do porte de Alcides Jorge Costa, Gastão Alves de Toledo, Helenilson Cunha Pontes e Ricardo Mariz de Oliveira, que a consideram um tributo de utilização excepcional e jamais um instrumento rotineiro de arrecadação que objetiva mascarar a notória incapacidade do esclerosado Estado brasileiro de reduzir despesas ${ }^{15}$. Merece, pois, reflexão a matéria. Que parlamentares não aprovem

\footnotetext{
I4 Ricardo Mariz de Oliveira lembra que: "Assim, há quem considere que as atuais possibilidades de intervenção da União restringern-se às formas indiretas de fiscalizaçăo, incentivo e planejamento, nos termos do art. 174, ou diretas de explotaça de atividades económicas thos termos do artigo 173, bem como as repressivas do abuso do poder económico ou de práticas contra a ordem econômica e financeira ou contra a economia popular, nos termos dos parágrafos $4^{\frac{a}{2}}$ e $5^{\frac{a}{2}}$ do artigo 173 .

Todavia, há que se encarar com cautela um tal posicionamento.

Realmente, não me parece que toda e qualquer forma interventiva, dentre as referidas, possa justificar a imposição de contribuição de intervenção no dominio econômico, muito embora em todas haja realmente uma forma de intervençấo.

Mas, por exemplo, não pode ser cobrada contribuição para punir excessos contra a liberdade de concorrência, ou contra a ordem econômica e financeira, ou contra a economia popular, pois excessos desta ordem são puniveis com multas pecuniánias ou outras penalidades. Aliás, por definição do CTN, nerhum tributo constitu sanção de ato ilicito (art. $3^{3}$ ).

Da mesma maneira, năo pode ser cobrada contribuiçäo para a Uniăo explorar diretamente uma atividade econômica, porque essa exploração deve se dar através de empresas públicas, sociedades de economia mista ou suas subsidiarias, as quais ficam sujeitas ao mesmo regime das empresas privadas e näo podem gozar de privilégios näo extensiveis às empresas privadas $\left(\S \S 1^{z}\right.$ e $2^{\ddagger}$ do art. 173).

$E_{3}$ no tocante ao ant. 174 , nem tudo o que a Uniâo pode fazer de acordo con o mesmo fustifica a instituição de uma contribuição interventiva, em virtude do caráter meramente indicativo -vale dizer, não obrigatório-do exexcicio da função de planejamento, ao passo a contribui̧̧ăo, como todo tributo, é obrigatónia. Sendo assim, há uma incompatibilidade inafastâvel entre a atividade de planejamento, meramente indicativa para o sctor privado, e a instituiçăo, sobre ela, de uma contribuiçào obrigatória" (Contribuiçôes de Intervençäo no dominio econônico ef figuras afins, ob. cit., p. 399/400).
} 
referidos projetos (a não ser, em casos excepcionais, de contribuiçôes que sejam verdadeiramente regulatórias e não apenas arrecadatórias) e que os magistrados estejam atentos a qualquer tentativa de se desfigurar o perfil das contribuições de intervenção no domínio econômico do Sistema Brasileiro.

15 Hugo de Brito Machado Segundo ensina: "Isso não é possivel, contudo, pois as contribuiçöes são pagas, essencialmente, para que certas finalidades sejam atendidas, e näo para que qualquer finalidade seja atendida. Além disso, admitir sentido lato para o termo "intervençăo tornaria sem sentido as demais competências, bem como as limitações a elas impostas; d) na verdade, as intervençöes no domínio econòmico que podem ser colhidas como finalidade para a contribuição em exame sã́o aquelas fixadas pela própria Constituiçá, notadamentê em sen Título VII (art. 170 e seguintes); e) alérn disso, tanto a contribuição de intervenção deve, ao incidir, realizar uma funço interventiva, através da extrafiscalidade, como o produto de sua arrecadação deve ser aplicado na consecução de atividades vinculadas a essa mesma finalidade. Admitir apenas uma dessas duas condiçôes como necessária a caracterizaçâo da espécic implica autotizar, pela metade, o desvio de sua finalidade" (Contribuiçôes de Intervenção no dominio econômico e figuras ahins, ob. cit Dialética, p. 129). 